\title{
The nurse under physician authority: commentary
}

\author{
Louise de Raeve University College of Swansea, Wales
}

As a nurse it is difficult for me to read this paper without feeling somewhat 'prickly' but at the same time I welcome May's attempt to address an unfashionable topic, which needs some debate. Why the defensiveness? It follows from certain statements May makes, for example his assertion that full colleague status for nurses with doctors, is connected with nurses taking on 'certain responsibilities to do with diagnosis and assessment, and even with the determination of range of treatments'. This assertion isn't of course untrue. Nurse practitioners who work in this way clearly have enhanced status but the point is that nursing status is yet again being assessed on medical terms: the 'other' dimensions of nursing are not seen to be equally but differently 'other'. Later in his paper May tries to redress this by referring to nurses' 'complex and sophisticated education' and the extension of their role beyond medicine. Is it undue sensitivity on my part that finds this faintly patronising rather than reassuring? $\mathrm{Be}$ this as it may, these issues are not central to the paper's argument and I now want to consider the question of authority.

It is certainly true that a traditional part of the doctor-nurse relationship has been the practice of physicians ordering treatment and nurses complying. May doesn't clarify precisely what is to be included in the concept of 'medical treatment' but historically, medication, dressings, and nursing care have all been seen to be legitimate areas of medical prescription. That this is now a shrinking arena of medical control would probably not be disputed but heated disputes might arise as to where precisely the line should be drawn and even as to whether such a line can be drawn, ie might some degree of ambiguity be essential? Nevertheless within rough parameters, it would probably be agreed that nursing care is no longer an appropriate focus of medical authority; medication remains legitimately so (although when introduced, nurse prescribing will begin to impinge on this) and dressings remain a somewhat ambiguous area, with the outcome determined by context.

\section{Key words}

Authority; practical reason; medical ethics
May uses Raz's (1) argument of second-order reasoning to support the idea that where physician authority is perceived to be legitimate, this should count, not as one reason amongst others, for obeying the doctor's orders but as a pre-emptive reason, given certain provisos such as dosage being within the normal range. Clearly, where the discrepancy between medical and nursing knowledge remains, an authoritative relationship has to persist. It is the authority of the informed over the relatively ignorant and is justified by the best interests of the patient. This conception of authority hardly seems to require May's defence, since the nurse is not capable of carrying out an independent firstorder level of reasoning. However, where nurses do have considerable pharmacological knowledge, as nurse prescribers will inevitably have, this picture will of course change. Does May's analysis help here?

Clearly it is in nobody's interests for nurses to be raising objections about medical prescriptions simply as a challenge to medical power. This would be obstructive and unprofessional but where nurses have appropriate knowledge and a genuine concern, they have a moral and professional responsibility to raise the question (2). This is because nurses are not accountable to doctors except for the carrying out of tasks that they have implicitly or explicitly agreed to do; rather they are accountable to patients, to the public and to their own professional body. A defence of 'doctor's orders' is no defence for a nurse in law. It seems to me therefore, that a doctor's legitimate authority (as distinct from power) over a nurse is only of the very minimalist sort that Raz sees contained in Friedman's remarks. Raz writes: ' $\ldots$ the minimalist interpretation maintains that they are willing to obey if they have no judgement of their own on the merits of performing the required action. They will not then defer decision until they form their own judgement' (3). Once nurses are able to form their own judgement, then it seems to me that professionally they are compelled to use it. May's argument therefore, has to be rejected.

It appears inevitable that as nursing education improves, combined perhaps with changes in the social position of women, doctors are going to have 
to face increasing questioning of their judgement by nurses. Responding by trying to clarify, in general, the domain of legitimate medical authority may not be helpful, for where good collegial relationships already exist between doctors and nurses, such questioning of doctors by nurses and vice versa will be experienced as helpful mutual scrutiny. Where relationships are strained or people are simply not used to working together in this way, such open questioning will probably be experienced as interfering and unnecessarily aggressive (4). However, will a generalised clarification of roles actually help this dynamic? It is perhaps a weakness of May's paper that he writes in such general terms, without recourse to particular examples. It may be that these kinds of difficulties are not best dealt with by prescriptive general statements about how people ought to work together but rather by detailed contextual understanding of why particular difficulties occurred. Armed with this kind of approach, people may well be able to resolve much for themselves and the rest of us tom learn through example (5).

Louise de Raeve, $B A, R G N$, is Macmillan Lecturer in $\vec{\Rightarrow}$ Nursing Ethics at the Centre For Philosophy and Health $\stackrel{\text { ? }}{+}$ Care, University College of Swansea, Swansea SA2 8PP.

\section{References}

(1) Raz J. Practical reasoning. Oxford: Oxford University Press, 1978: ch IX.

(2) UKCC. Exercising accountability, 1989; UKCC Code of professional conduct, 1992 and UKCC The scope of $\vec{\omega}$ professional practice, 1992.

(3) Raz J. The morality of freedom. Oxford: Clarendon Press, 1988: 40.

(4) Stein L. The doctor nurse game. In: Dingwall $R, \vec{\omega}$ McIntosh $\mathrm{J}$ eds. Readings in the sociology of nursing. Edinburgh: Churchill Livingstone, 1978.

(5) Pike A W. Moral outrage and moral discourse in $\infty$ nurse-physician collaboration. Fournal of professional 옥 nursing 1991; 7, 6: 351-363.

\section{News and notes}

\section{Teaching Research Ethics: a Workshop at Indiana University}

Indiana University's Poynter Center for the Study of Ethics and American Institutions will offer, annually for the next three years, a workshop in teaching research ethics to scientists in the Midwest who train graduate students.

The need for explicit training in research ethics for scientists is widely recognized; mentoring and modelling ethical behaviour are no longer considered sufficient. Several federal agencies, including the National Institutes of Health (NIH) and the Alcohol, Drug Abuse and Mental Health Administration (ADAMHA) now require training in the responsible conduct of research as part of their National Research Service Awards training grants. Many science faculty are eager to include research ethics in their curricula, but their training is in science, not in teaching ethics. The Poynter Center's workshop, entitled 'Teaching Research Ethics,' will provide the necessary training.

The week-long workshop will be conducted in early summer for twenty to thirty faculty members drawn from university members of the Committee for Institutional Co-operation (the Big Ten plus the University of Chicago).

The five-day workshop will be followed by a one-day conference, which will be open to the wider academic community. The conference will feature a keynote address by a speaker of national prominence and panel discussions on a substantive issue in research ethics. In years two and three, alumni/ae of the workshop will report on their experiences and progress in incorporating research ethics into their curricula.

The workshop has the potential to have a significant impact on a number of universities in the Midwest, affecting faculty, students, and the institutions as a whole. Faculty participating in the workshop will be able to design syllabi or course units integrating substantive issues in research ethics and will gain competence and confidence in teaching research ethics. Students of participating faculty will develop better moral reasoning skills and will be better able to recognize and act on ethical issues. Institutions of participating faculty will build a greater commitment to, and expertise and history in, incorporating research ethics in science curricula.

For more information: Kenneth D Pimple, $\mathrm{PhD}$, Indiana University, The Poynter Center for the Study of Ethics and American Institutions, 410 North Park Avenue, Bloomington, Indiana 47405; Tel: (812) 855-0261; Fax: (812) 8553315; Bitnet: PIMPLE@INDIANA; Internet: PIMPLE@INDIANA.EDU. 